\title{
Whistle mouth pressure as test of expiratory muscle strength
}

\author{
A. Chetta*,\#, M.L. Harris*, R.A. Lyall*, G.F. Rafferty*, M.I. Polkeyף, D. Olivieri", J. Moxham*
}

Whistle mouth pressure as test of expiratory muscle strength. A. Chetta, M.L. Harris, R. A. Lyall, G.F. Rafferty, M.I. Polkey, D. Olivieri, J. Moxham. (C)ERS Journals Ltd 2001.

ABSTRACT: Expiratory muscle strength is a determinant of cough function. Mouth pressures during a maximal static expiratory effort $(P E, \max )$ are dependent on patient motivation and technique and low values are therefore difficult to interpret. This study hypothesized that a short, sharp and maximal expiration through a narrow aperture, a "whistle", might provide a complementary test of expiratory muscle strength.

To obtain a maximal whistle, subjects (27 healthy volunteers and 10 patients with amyotrophic lateral sclerosis) were asked to perform a short, sharp blow as hard as possible, from total lung capacity, through a reversed paediatric inhaler whistle, connected to a flange-type mouthpiece.

In both healthy subjects and patients, whistle mouth pressure $\left(P_{m o}, w\right)$ was closely related to the pressure measured in the oesophagus and stomach during the same manoeuvre. In healthy subjects, $\boldsymbol{P}_{\mathrm{mo}, \mathrm{W}}$ and $\boldsymbol{P E}$,max correlated with wide limits of agreement, although $P_{\text {mo, }}$ values were significantly higher than $P$ E,max $\left(131 \pm 31 \mathrm{cmH}_{2} \mathrm{O}\right.$ versus $\left.101 \pm 27 \mathrm{cmH}_{2} \mathrm{O}, \mathrm{p}<0.0001\right)$. In patients, it was also found that $P_{\mathrm{mo}, \mathrm{W}}$ and $P \mathrm{E}$,max values were strongly related $(r=0.937, p<0.0001)$. In healthy subjects, the intraclass correlation coefficient and the variation coefficient for $\boldsymbol{P} \mathbf{m o}, \mathrm{W}$ repeated measurements were respectively 0.88 and $7.0 \%$. However $P_{m o, W}$ and $P E$,max were always smaller than the gastric pressure generated by a maximal cough.

It is concluded that mouth whistle pressure, a noninvasive, reproducible and simple test, provides a reliable measure of expiratory muscle strength in healthy subjects that is acceptable to patients and can be used in a complementary fashion to maximal static expiratory effort.

Eur Respir J 2001; 17: 688-695.

\author{
*Dept of Respiratory Medicine \& \\ Allergy, Guy's, King's \& St. Thomas' \\ School of Medicine, King's College \\ Hospital, London, UK. " Dept of \\ Respiratory Diseases, University of \\ Parma, Italy. "Respiratory Muscle \\ Laboratory, Royal Brompton Hospital, \\ London, UK. \\ Correspondence: A. Chetta \\ Istituto di Malattie Respiratoire \\ Azienda Ospedaliera e Università di \\ Parma \\ Viale G. Rasori 10 \\ Parma \\ Italy \\ Fax: 390521292615
}

Keywords: Expiratory muscle strength respiratory muscles

respiratory pressures

whistle mouth pressure test

Received: June 192000

Accepted after revision November 13 2000
Chest infection is a cause of serious morbidity and mortality in patients with respiratory and neuromuscular disease. Cough is considered to protect against chest infection and it has recently been shown that expiratory muscle strength is an important determinant of an effective cough [1]. Techniques to evaluate expiratory muscle strength are therefore of interest.

Mouth pressures during maximal static expiratory $(P \mathrm{E}, \mathrm{max})$ efforts are widely used as a noninvasive test to assess expiratory muscle strength [2]. When high values are found, muscle weakness is excluded [3]. However, the normal range for $P \mathrm{E}$,max is wide [2, 4], reflecting both the biological variability of respiratory muscle strength and also the difficulty some subjects have in performing the manoeuvre maximally. In the assessment of inspiratory muscle strength it has been shown that the use of a manoeuvre complementary to the static effort, such as the maximal sniff, can exclude inspiratory muscle weakness $[5,6]$. Indeed sniffing is a natural manoeuvre which is more easily performed than static efforts, and by measuring the upper airway pressure during a maximal sniff, inspiratory muscle strength may now be accurately measured noninvasively [7] in a variety of clinical settings $[8]$.
It was therefore reasoned that an additional test of expiratory muscle strength that was noninvasive, using a natural, uncomplicated manoeuvre, could be clinically useful. The main muscles of expiration are the abdominal muscles and one approach to measuring their strength is to record gastric pressure during a maximal cough [1] or following magnetic nerve stimulation posteriorly at the level of the 10th thoracic intervertebral space [9]. However, both these tests require passage of a gastric balloon catheter. The present authors hypothesized that a test using pressure measured at the mouth during a short, sharp and maximal expiration through a narrow aperture (a "whistle") would be a relatively natural manoeuvre that might be a useful additional noninvasive test of expiratory muscle strength. The main purpose of the study was to ascertain in healthy subjects, and in patients with respiratory muscle weakness, whether the measurement of mouth pressure during a whistle manoeuvre $(P \mathrm{mo}, \mathrm{W})$ is reproducible, and whether mouth whistle was pressure closely reflects oesophageal and gastric pressures. In addition, the study aimed to compare mouth, oesophageal and gastric pressures during whistle and $P$ E,max manoeuvres, as well as to compare whistle mouth pressure to gastric pressure, during a maximum cough. 


\section{Methods}

Twenty-seven healthy volunteers (10 male) and 10 patients (all male) with amyotrophic lateral sclerosis (ALS) were studied. The severity of ALS was assessed by the Norris limb and bulbar scales [10] and by the ALS functional rate scale [11]. The study was approved by the hospital ethics committee and all subjects gave their informed consent.

Spirometry was measured by a horizontal bellows spirometer (Vitalograph Ltd, Buckingham, UK) and vital capacity (VC), forced expiratory volume in one second (FEV1) and FEV1/VC values were recorded. Predicted values of $\mathrm{VC}$ and $\mathrm{FEV} 1$ were obtained from regression equations by QUANJER et al. [12].

In order to obtain a maximal whistle, subjects were asked to perform a short, sharp blow as hard as possible from total lung capacity (TLC) through a reversed paediatric inhaler whistle (Astra Pharmaceuticals Ltd, Herts, UK) connected to a flange-type mouthpiece gripped between the teeth (fig. 1). Subjects performed whistles without a noseclip. Additionally, healthy subjects were asked to perform maximum whistles while holding their cheeks. Whistles suitable for analysis had to present pressure tracings showing a sharp peak and a duration of $<500 \mathrm{~ms}$. This was usually achieved after 3-6 whistle manoeuvres. Healthy subjects were also asked to perform whistles of varying intensities. Repeatability of whistle mouth pressure $(P \mathrm{mo}, \mathrm{W})$ in healthy subjects was assessed by repeating measurements on two separate days. The whistle device had a linear relationship between resistance and flow across the range $10-100 \mathrm{~L} \cdot \mathrm{min}^{-1}$. The mean (range) value for peak flow through the device for healthy subjects was $92 \mathrm{~L} \cdot \mathrm{min}^{-1}\left(78-109 \mathrm{~L} \cdot \mathrm{min}^{-1}\right)$. The resistance over this range was $29.3-44.4 \mathrm{cmH}_{2} \mathrm{O} \cdot \mathrm{L}^{-1} \cdot \mathrm{s}$.

$P$ E,max and maximal static inspiratory effort $(P I, \max )$ were performed against a valve based on that used by BLACK and HyatT [4] which could be closed by turning a tap. A leak $3.7 \mathrm{~cm}$ in length and $0.2 \mathrm{~cm}$ in diameter was placed $3 \mathrm{~cm}$ from the mouthpiece to reduce

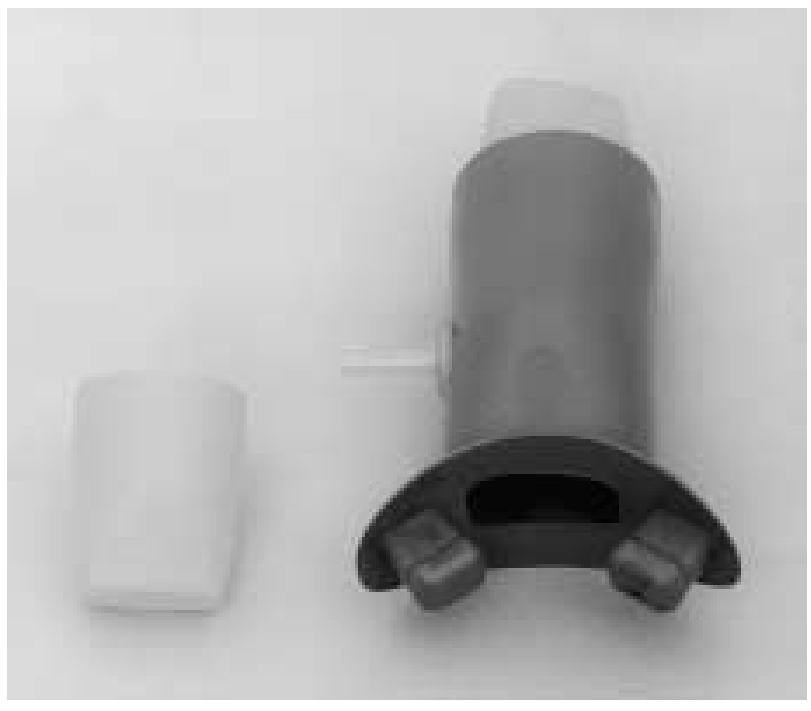

Fig. 1. - The whistle device consists of a reversed paediatric inhaler whistle connected to a conventional mouthpiece. discomfort and generation of high buccal pressures [13]. A conventional flanged mouthpiece and noseclip were used. PE,max was measured from TLC and PI,max from residual volume. The highest recorded pressures maintained for one second were used for analysis. Patients attempted to prevent perioral leak by holding their lips firmly around the mouthpiece with both hands. Day-to-day reproducibility of $P \mathrm{E}, \max$ was assessed in the healthy subjects.

Gastric $(P$ ga $)$, oesophageal $\left(P_{\text {oes }}\right)$ and transdiaphragmatic $(P \mathrm{di})$ pressures were measured using a pair of commercially available latex balloon catheters (PK Morgan, Rainham, Kent, UK) $110 \mathrm{~cm}$ in length, passed through the nose and positioned in the stomach and oesophagus in the conventional manner [14]. The oesophageal balloon contained $0.5 \mathrm{~mL}$ air, the gastric balloon $2 \mathrm{~mL}$.

$P$ ga during a maximum voluntary cough effort, was also measured in healthy subjects and patients. This manoeuvre was performed in a seated position without a noseclip. Invariably, subjects inhaled deeply before coughing, but no specific instructions were given regarding the magnitude of inspiration before cough. Repeated efforts were performed until no further increase in $P$ ga was obtained (usually achieved after 3-6 coughs).

The whistle device, the mouth piece and the balloon catheters were connected to differential pressure transducers (Validyne MP45-1, Validyne, Northridge, CA, USA), carrier amplifiers (PK Morgan), a 12 bit NBMIO-16 analogue-digital board (National Instruments, Austin, TX, USA) and a Macintosh Quadra Centris 650 personal computer (Apple Computer Inc., Cupertino, CA, USA) running Labview ${ }^{\mathrm{TM}}$ software (National Instruments). $P$ di was obtained on-line, by subtraction of $P$ oes from $P$ ga. A minimum sampling frequency of $100 \mathrm{~Hz}$ was used. Peak pressures were taken as those measured from the baseline at relaxed end-expiratory lung volume, at the peak pressure, obtained.

Healthy subjects and patients were studied in the seated position and pressures were displayed on a computer screen in front of the subject to provide visual feedback [15]. Subjects were strongly encouraged to make maximal efforts.

Data are presented as mean \pm SD. VC and FEV1 values were expressed as per cent of predicted value, FEV1/VC is expressed as per cent. Differences in numerical data were examined by means of paired $t-$ tests. The agreement between measures was assessed by the method of differences against the means according to Bland and Altman [16]. The relationship between measures was assessed by Pearson's correlation coefficient $(r)$ and linear regression analysis. The repeatability of measures was expressed as intraclass correlation coefficient (rI) [17] and assessed by calculating the coefficient of variation. A p-value $<0.05$ was considered statistically significant.

\section{Results}

\section{Healthy subjects}

Personal details were: age, $32 \pm 6$ yrs; height, $170 \pm 10$ $\mathrm{cm}$; weight, $68 \pm 13 \mathrm{~kg}$; and body mass index, $24 \pm 4$ 
$\mathrm{kg} \cdot \mathrm{m}^{-2}$. Spirometric values were: VC, $104 \pm 13 \%$ pred; FEV1, 104 $\pm 14 \%$ pred; FEV1/VC, $83 \pm 7 \%$.

In the 27 healthy subjects, $P$ mo,W and $P$ E,max values

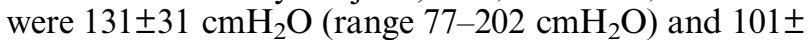
$27 \mathrm{cmH}_{2} \mathrm{O}$ (range $44-155 \mathrm{cmH}_{2} \mathrm{O}$ ), respectively ( $\mathrm{p}<$ $0.0001)$. The $95 \%$ confidence intervals of the mean were $119-143 \mathrm{cmH}_{2} \mathrm{O}$ for $P \mathrm{mo}, \mathrm{W}$ and $90-111 \mathrm{cmH}_{2} \mathrm{O}$ for $P$ E,max. In the same group of subjects, $P$ mo, W did not differ from $P$ mo, $\mathrm{W}$ obtained while holding cheeks $\left(139 \pm 35 \mathrm{cmH}_{2} \mathrm{O}\right.$, range $\left.72-217 \mathrm{cmH}_{2} \mathrm{O}\right)$. The ratio $P$ mo,W/PE,max was 1.3 (range $0.9-2.1$ ) and in 24 out of 27 subjects, was $>1$. There was a significant correlation between $P$ mo, W and $P$ E, max $(\mathrm{r}=0.674, \mathrm{p}=0.0001)$ (fig. 2). The bias between $P$ mo, $\mathrm{W}$ and $P$ E,max was 30 $\mathrm{cmH}_{2} \mathrm{O}$, with $P$ mo, W tending to be numerically greater than $P$ E,max. The limits of agreement ranged from -17$77 \mathrm{cmH}_{2} \mathrm{O}$ (fig. 2). The rI and the variation coefficient for $P$ mo,W repeated measurements were 0.888 and $7.0 \%$, respectively. In the same group of subjects, rI and variation coefficient for $P \mathrm{E}, \max$ were 0.790 and $10.2 \%$, respectively.

In the 12 subjects in whom $P$ oes, $P$ ga and $P$ di were measured during both the whistle and $P$ E,max manoeuvres, values were respectively: $P$ mo, W $139 \pm 27 \mathrm{cmH}_{2} \mathrm{O}$
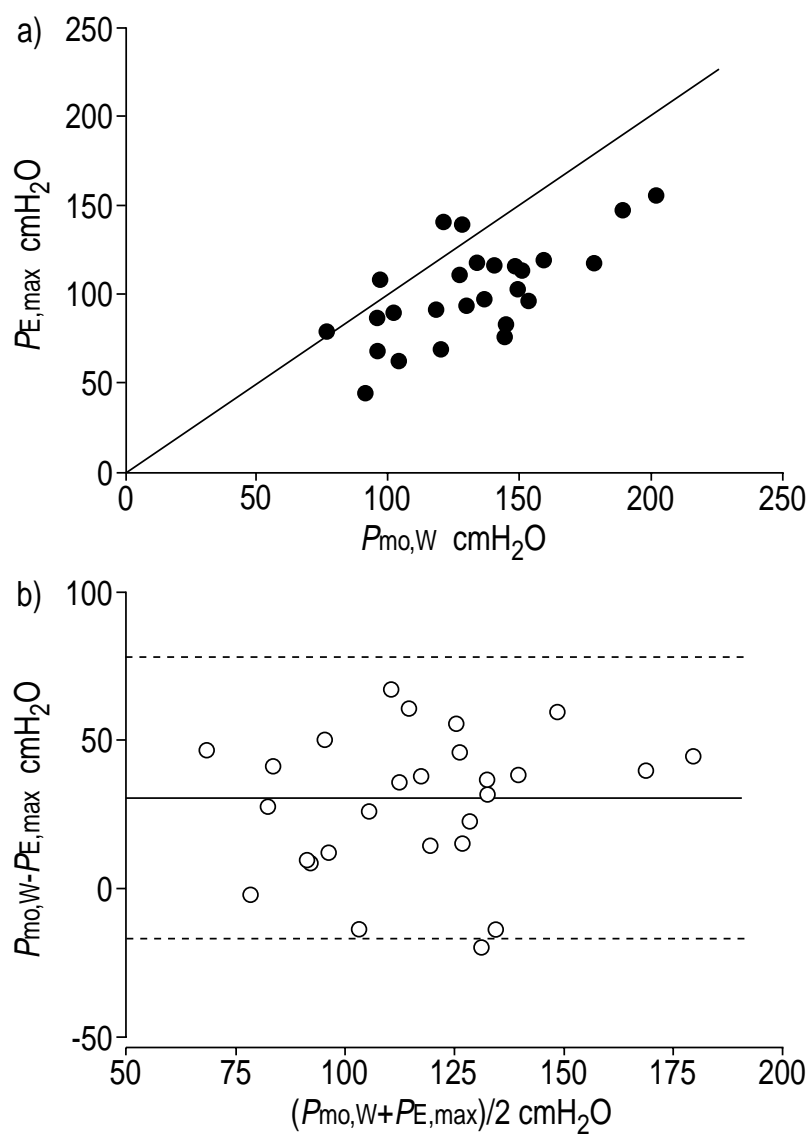

Fig. 2. - a) Relationship between mouth whistle pressure $(P$ mo,w) and maximum expiratory pressure $(P \mathrm{E}, \max )$ in 27 healthy subjects. The continuous line is the line of identity. $r=0.67, p=0.0001 . b$ ) Plot of the difference between $P$ mo,W and $P$ E,max against the mean of $P$ mo,W and $P$ E,max in 27 healthy subjects. The bias, i.e. the mean of the difference between $P$ mo,w and $P$ E,max (continuous line), was $30 \mathrm{cmH}_{2} \mathrm{O}$; the limits of agreement, i.e. bias $\pm 2 \mathrm{SD}$ (interrupted lines), were $-17-77 \mathrm{cmH}_{2} \mathrm{O}$. and $P$ E,max $109 \pm 27 \mathrm{cmH}_{2} \mathrm{O}(\mathrm{p}<0.02), P_{\text {oes }} \mathrm{W} 129 \pm 20$ $\mathrm{cmH}_{2} \mathrm{O}$ and $P$ oes, $P$ E,max $109 \pm 24 \mathrm{cmH}_{2} \mathrm{O}(\mathrm{p}<0.05), P$ ga, $W$ $163 \pm 36 \mathrm{cmH}_{2} \mathrm{O}$ and $P$ ga, $P$ E, max $160 \pm 60 \mathrm{cmH}_{2} \mathrm{O}$, and $P$ di,W $34 \pm 29 \mathrm{cmH}_{2} \mathrm{O}$ and $P$ di, $P$ E,max $50 \pm 51 \mathrm{cmH}_{2} \mathrm{O}$. The ratios of $P$ mo, $\mathrm{W} / P_{\mathrm{oes}}, \mathrm{W}$ and $P \mathrm{mo}, \mathrm{W} / P_{\mathrm{ga}}, \mathrm{W}$ were 1.1 (range $0.95-1.23)$ and $0.88(0.54-1.1)$, respectively. Biases between $P$ mo, $\mathrm{W}$ and $P_{\text {oes }}, \mathrm{W}$ (the mean of the difference between these two variables) and between $P$ mo, $\mathrm{W}$ and $P$ ga, $\mathrm{W}$ were $9 \mathrm{cmH}_{2} \mathrm{O}$ and $-26 \mathrm{cmH}_{2} \mathrm{O}$ and limits of agreement (bias $\pm 2 \mathrm{SD}$ ) ranged from -17$35 \mathrm{cmH}_{2} \mathrm{O}$ and from $-83-31 \mathrm{cmH}_{2} \mathrm{O}$ (fig. 3).

In the same group of subjects, the mean value of cough $P$ ga was $201 \pm 57 \mathrm{cmH}_{2} \mathrm{O}(\mathrm{p}<0.01$ versus $P$ mo, $\mathrm{W}$ and $P$ E,max $)$ and the $95 \%$ confidence intervals of the mean were $165-238 \mathrm{cmH}_{2} \mathrm{O}$. The ratios of $P$ mo,w/ cough $P$ ga and $P$ E, max/cough $P$ ga were 0.73 (range $0.40-1.23)$ and 0.57 (0.35-0.92). Biases between $P$ mo,W and cough $P$ ga and between $P$ E,max and cough $P$ ga were $-63 \mathrm{cmH}_{2} \mathrm{O}$ and $-90 \mathrm{cmH}_{2} \mathrm{O}$, respectively and limits of agreement ranged $-167-41 \mathrm{cmH}_{2} \mathrm{O}$ and $-193-13$ $\mathrm{cmH}_{2} \mathrm{O}$, respectively (fig. 4). A typical example of the pressures during whistle, $P$ E, max and maximal cough manoeuvres is shown in figure 5 .

In the 8 subjects, in whom $P$ mo, $, P_{\text {oes }}, \mathrm{W}$ and $P$ ga, $\mathrm{W}$ values were compared during whistles of variable intensity, $P$ mo, $, P_{\text {oes }}, \mathrm{W}$ and $P$ ga, $\mathrm{W}$ ranged $7-222$ $\mathrm{cmH}_{2} \mathrm{O}$, 4-161 $\mathrm{cmH}_{2} \mathrm{O}$ and 9-235 $\mathrm{cmH}_{2} \mathrm{O}$, respectively. There was a significant correlation between $P$ mo,W and $P$ oes, $\mathrm{W}(\mathrm{r}=0.929, \mathrm{p}<0.0001)$ and between $P$ mo,W and $P$ ga, $\mathrm{W}$ values $(\mathrm{r}=0.936, \mathrm{p}<0.0001)$ (table 1$)$. Regression analysis showed that $P$ mo, $=5.49+1.1 P$ ga,,$W$ and $P$ mo, $\mathrm{W}=7.27+0.8 P_{\text {oes }}, \mathrm{W}$.

\section{Patients}

Patients had ALS of varying severity. The mean Norris limb and bulbar scales were 28 \pm 14 (range 9-50) and $35 \pm 6$ (range 21-39), respectively. The mean ALS functional rating scale was $25 \pm 16$ (range 13-32). Their personal details were: age, $61 \pm 5$ yrs; height, $173 \pm$ $10 \mathrm{~cm}$; weight, $73 \pm 12 \mathrm{~kg}$; and body mass index, $24.4 \pm 3.7 \mathrm{~kg} \cdot \mathrm{m}^{-2}$. Spirometric values were: VC, $78 \pm 24$

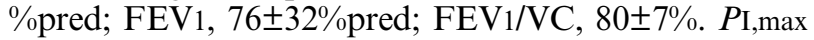
values were $56 \pm 28 \mathrm{cmH}_{2} \mathrm{O}$ (range $15-104 \mathrm{cmH}_{2} \mathrm{O}$ ).

The mean values of $P$ mo, $\mathrm{W}$ and $P$ E, max were $69 \pm$ $32 \mathrm{cmH}_{2} \mathrm{O}$ (range $17-128 \mathrm{cmH}_{2} \mathrm{O}$ ) and $62 \pm 30 \mathrm{cmH}_{2} \mathrm{O}$ (range 11-116 $\mathrm{cmH}_{2} \mathrm{O}$ ), respectively. The $95 \%$ confidence intervals of the mean were $46-92 \mathrm{cmH}_{2} \mathrm{O}$ for $P$ mo, W and $41-84 \mathrm{cmH}_{2} \mathrm{O}$ for $P$ E,max. The ratio $P$ mo,W/ $P$ E,max was 1.17 (0.87-1.55). There was a significant correlation between $P$ mo, $\mathrm{W}$ and $P$ E,max $(\mathrm{r}=0.937, \mathrm{p}<$ $0.0001)$. The bias between $P$ mo, $\mathrm{W}$ and $P$ E, max was $7 \mathrm{cmH}_{2} \mathrm{O}$ and the limits of agreement ranged -15$29 \mathrm{cmH}_{2} \mathrm{O}$ (fig. 3).

The mean $P_{\text {oes, }} P$ ga, and $P$ di values during both whistle and $P E$, max manoeuvres were $66 \pm 32 \mathrm{cmH}_{2} \mathrm{O}$ and $63 \pm 29 \mathrm{cmH}_{2} \mathrm{O}, 74 \pm 37 \mathrm{cmH}_{2} \mathrm{O}$ and $56 \pm 33 \mathrm{cmH}_{2} \mathrm{O}$ $(\mathrm{p}<0.02)$, and $8 \pm 7 \mathrm{cmH}_{2} \mathrm{O}$ and $-7 \pm 10 \mathrm{cmH}_{2} \mathrm{O}(\mathrm{p}<0.002)$, respectively. The ratios of $P$ mo,w/Poes, W and $P$ mo,w/ $P$ ga, W were 1.08 (range 0.82-1.31) and 1.17 (range 0.871.55 ). Biases between $P$ mo, $\mathrm{W}$ and $P_{\mathrm{oes}}, \mathrm{W}$ and between $P$ mo, $\mathrm{W}$ and $P$ ga, $\mathrm{W}$ were $3 \mathrm{cmH}_{2} \mathrm{O}$ and $-5 \mathrm{cmH}_{2} \mathrm{O}$, respectively and limits of agreement ranged $-10-16$ 

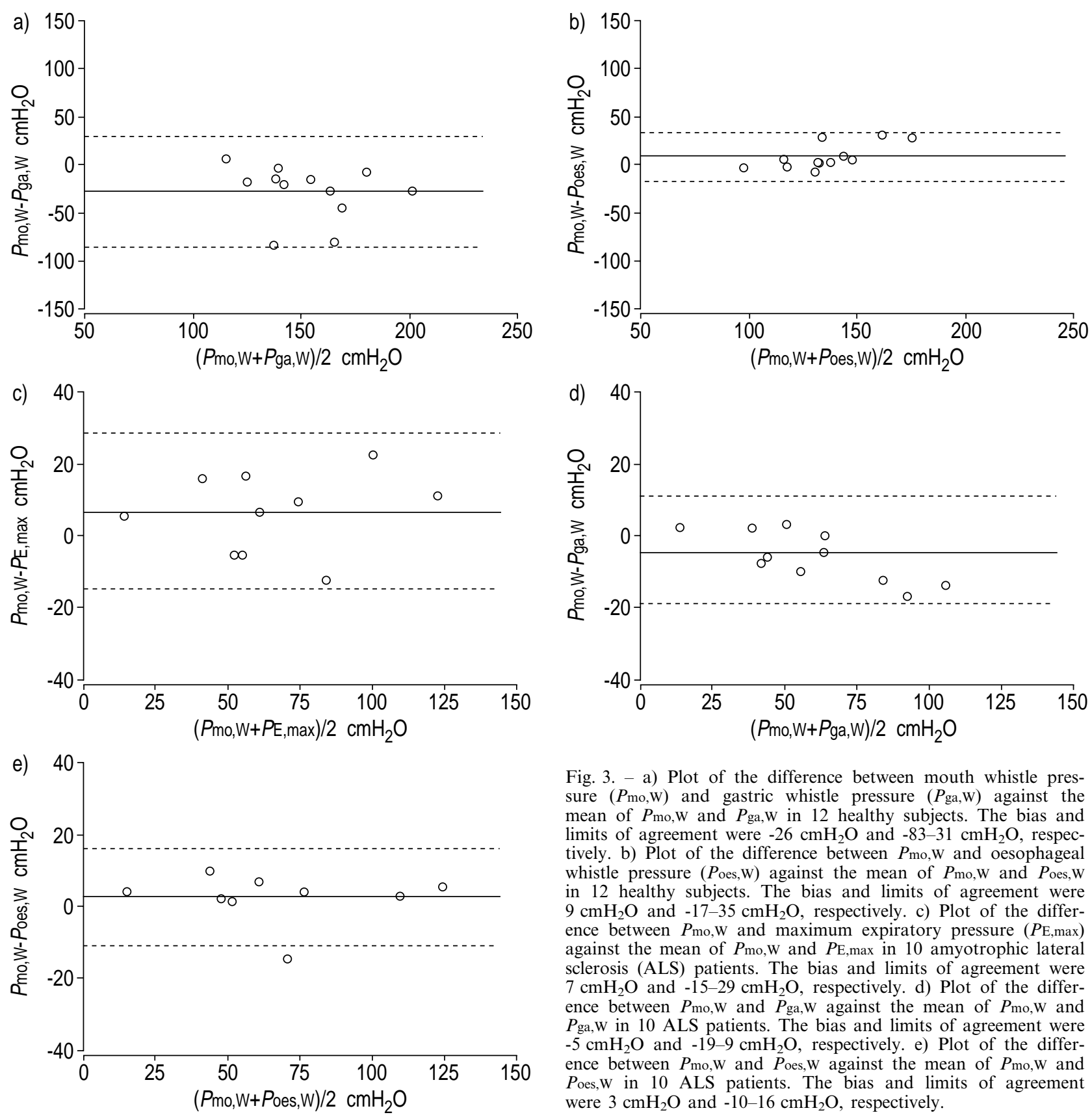

$\mathrm{cmH}_{2} \mathrm{O}$ and -19-9 $\mathrm{cmH}_{2} \mathrm{O}$ (fig. 3). There was a significant correlation between $P$ mo, W and $P$ oes, W $(\mathrm{r}=0.980$, $\mathrm{p}<0.0001)$ and between $P$ mo,W and $P$ ga, $\mathrm{W}$ values $(\mathrm{r}=0.990, \mathrm{p}<0.0001)$. Regression analysis showed that $P$ mo, $\mathrm{W}=-5.33+1.1 P$ ga, $\mathrm{W}$ and $P \mathrm{mo}, \mathrm{W}=-1.78+0.9 P$ oes, $\mathrm{W}$.

The mean value of cough $P$ ga was $85 \pm 39 \mathrm{cmH}_{2} \mathrm{O}$ $(\mathrm{p}<0.05$ versus $P \mathrm{E}, \max )$ and the $95 \%$ confidence intervals of the mean were $57-112 \mathrm{cmH}_{2} \mathrm{O}$. Ratios of $P$ mo,w/ cough $P$ ga and $P$ E,max/cough $P$ ga were 0.88 (range 0.50 $1.39)$ and $0.78(0.44-1.36)$, respectively. Biases between $P$ mo,W and cough $P$ ga and between $P$ E,max and cough $P$ ga were $-16 \mathrm{cmH}_{2} \mathrm{O}$ and $-23 \mathrm{cmH}_{2} \mathrm{O}$, respectively, and limits of agreement ranged $-75-43 \mathrm{cmH}_{2} \mathrm{O}$ and $-91-$ $45 \mathrm{cmH}_{2} \mathrm{O}$, respectively (fig. 4). There was a significant correlation between $P$ mo, $\mathrm{W}$ and cough $P$ ga $(\mathrm{r}=0.67$, $\mathrm{p}<0.05)$.

Fig. 3. - a) Plot of the difference between mouth whistle pressure $(P \mathrm{mo}, \mathrm{W})$ and gastric whistle pressure $(P \mathrm{ga}, \mathrm{W})$ against the mean of $P$ mo,W and $P$ ga, W in 12 healthy subjects. The bias and limits of agreement were $-26 \mathrm{cmH}_{2} \mathrm{O}$ and $-83-31 \mathrm{cmH}_{2} \mathrm{O}$, respectively. b) Plot of the difference between $P$ mo, $\mathrm{W}$ and oesophageal whistle pressure $\left(P_{\text {oes }}, \mathrm{W}\right)$ against the mean of $P$ mo,W and $P$ oes, W in 12 healthy subjects. The bias and limits of agreement were $9 \mathrm{cmH}_{2} \mathrm{O}$ and $-17-35 \mathrm{cmH}_{2} \mathrm{O}$, respectively. c) Plot of the difference between $P$ mo, $\mathrm{W}$ and maximum expiratory pressure $\left(P_{\mathrm{E}, \max }\right)$ against the mean of $P \mathrm{mo}, \mathrm{W}$ and $P \mathrm{E}, \max$ in 10 amyotrophic lateral sclerosis (ALS) patients. The bias and limits of agreement were $7 \mathrm{cmH}_{2} \mathrm{O}$ and $-15-29 \mathrm{cmH}_{2} \mathrm{O}$, respectively. d) Plot of the difference between $P$ mo,W and $P$ ga, W against the mean of $P$ mo,W and $P$ ga, $\mathrm{W}$ in 10 ALS patients. The bias and limits of agreement were $-5 \mathrm{cmH}_{2} \mathrm{O}$ and $-19-9 \mathrm{cmH}_{2} \mathrm{O}$, respectively. e) Plot of the difference between $P$ mo, $\mathrm{W}$ and $P$ oes, W against the mean of $P$ mo,W and $P_{\text {oes, }} \mathrm{W}$ in 10 ALS patients. The bias and limits of agreement were $3 \mathrm{cmH}_{2} \mathrm{O}$ and $-10-16 \mathrm{cmH}_{2} \mathrm{O}$, respectively.

\section{Discussion}

The main finding of this study was that pressure measured at the mouth during a short sharp whistle has a close relationship with the pressure measured in the oesophagus and stomach during the same manoeuvre. This confirms that this measurement $(P \mathrm{mo}, \mathrm{W})$ is a valid reflection of expiratory muscle strength. The studies, conducted in normal subjects and patients with expiratory muscle weakness, show that the limits of agreement with the $P \mathrm{E}$,max are wide; i.e. high values of $P$ mo,w could be obtained when $P$ E,max was low and, less often, high values of $P E$,max were observed when $P$ mo, W was low. This suggests that $P$ mo,W and $P$ E,max are complementary tests for the noninvasive evaluation of expiratory muscle strength. However, when 

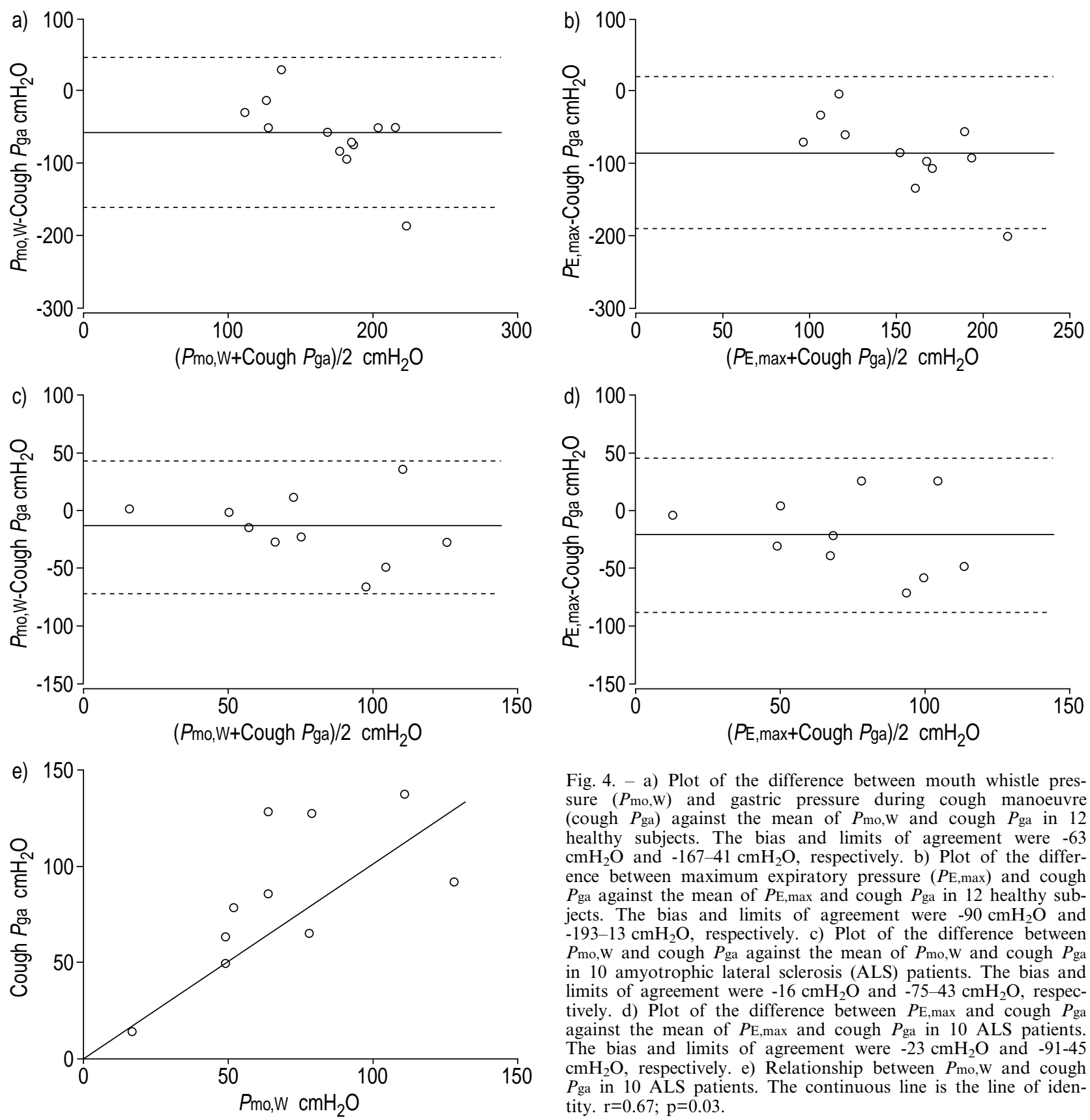

Fig. 4. - a) Plot of the difference between mouth whistle pressure $(P \mathrm{mo}, \mathrm{W})$ and gastric pressure during cough manoeuvre (cough $P_{\text {ga }}$ ) against the mean of $P_{\mathrm{mo}, \mathrm{W}}$ and cough $P_{\mathrm{ga}}$ in 12 healthy subjects. The bias and limits of agreement were -63 $\mathrm{cmH}_{2} \mathrm{O}$ and $-167-41 \mathrm{cmH}_{2} \mathrm{O}$, respectively. b) Plot of the difference between maximum expiratory pressure $(P \mathrm{E}, \max )$ and cough $P$ ga against the mean of $P$ E,max and cough $P_{\text {ga }}$ in 12 healthy subjects. The bias and limits of agreement were $-90 \mathrm{cmH}_{2} \mathrm{O}$ and $-193-13 \mathrm{cmH}_{2} \mathrm{O}$, respectively. c) Plot of the difference between $P$ mo, W and cough $P$ ga against the mean of $P$ mo,W and cough $P$ ga in 10 amyotrophic lateral sclerosis (ALS) patients. The bias and limits of agreement were $-16 \mathrm{cmH}_{2} \mathrm{O}$ and $-75-43 \mathrm{cmH}_{2} \mathrm{O}$, respectively. d) Plot of the difference between $P$ E, max and cough $P$ ga against the mean of $P$ E,max and cough $P$ ga in 10 ALS patients. The bias and limits of agreement were $-23 \mathrm{cmH}_{2} \mathrm{O}$ and $-91-45$ $\mathrm{cmH}_{2} \mathrm{O}$, respectively. e) Relationship between $P$ mo,W and cough $P$ ga in 10 ALS patients. The continuous line is the line of identity. $\mathrm{r}=0.67 ; \mathrm{p}=0.03$.

compared to the gastric pressure during maximal cough, both $P$ mo, $\mathrm{W}$ and $P$ E,max underestimate expiratory muscle strength. Further discussion of the significance of the findings follows a critique of the method.

\section{Critique of the method}

Do mouth measurements reflect expiratory muscle strength? The aim of the study was to develop a test which reflected abdominal muscle strength, since these muscles are the main muscles of active expiration and are an important determinant of cough function. In the present study, $P$ ga was almost inva-

riably greater than $P_{\text {oes }}$ during both $P$ mo,W and $P$ E,max indicating that the abdominal muscles are the driving force in both manoeuvres. In healthy subjects, for whom $P_{\text {oes, }} P$ ga and $P$ di were measured during both manoeuvres, $P$ ga was similar for both manoeuvres, though $P$ oes was different, resulting in higher $P$ di values with $P$ E,max compared to $P$ mo,W. This suggests that $P$ mo, W may be a more accurate reflection of abdominal muscle strength than $P$ E,max.

However, for the group as a whole, $P$ ga was incompletely transmitted from the abdomen to the chest; thus $P$ oes was $79 \%$ and $68 \%$ of $P$ ga during whistle and $P$ E,max manoeuvres, respectively. The reduced transmission of gastric pressure could be the result of 


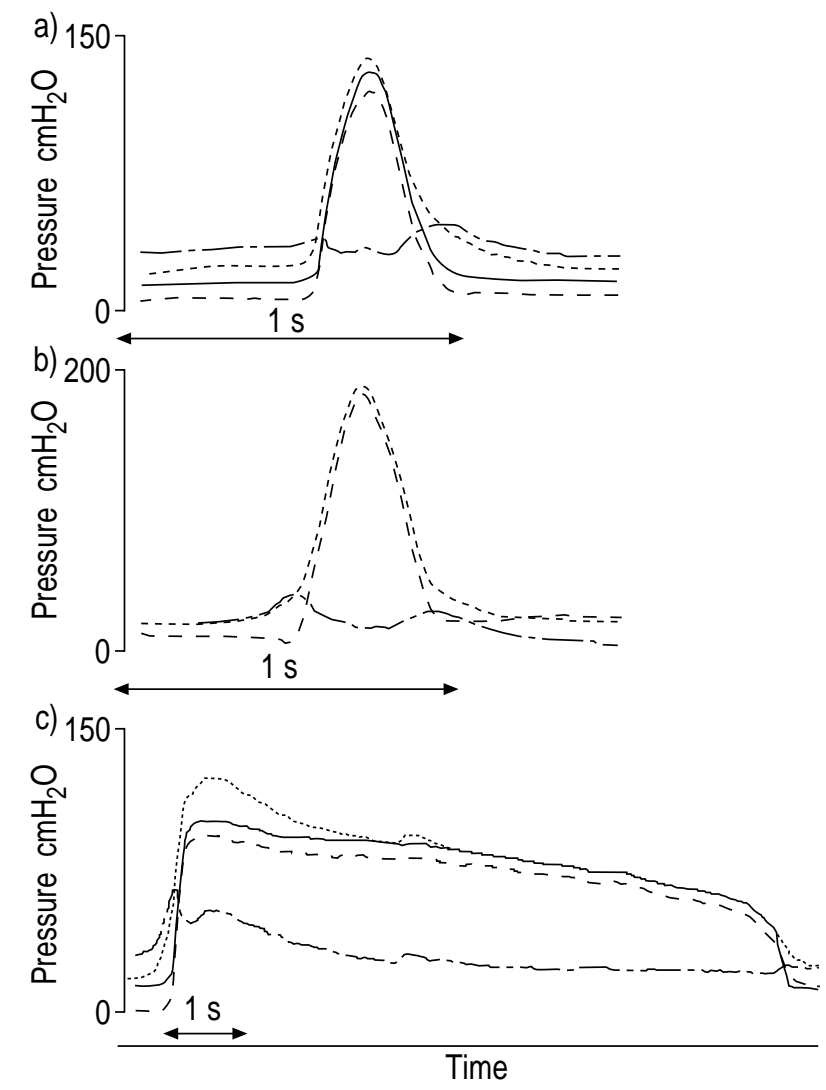

Fig. 5. - Pressures produced by: a) maximal whistle; b) maximal cough; and c) maximum expiratory pressure $(P \mathrm{E}, \max )$ manoeuvres by a healthy subject. - - mouth pressure; -- : oesophageal pressure; - - - : gastric pressure; — -: transdiaphragmatic pressure.

diaphragm activation and the "inspiratory" action of the abdominal muscle on the lower rib cage $[19,20]$. As further confirmation that $P$ mo, W closely reflects both $P_{\text {oes, }} \mathrm{W}$ and $P$ ga, W, a strong correlation between $P$ mo, W and $P$ ga, W and between $P$ mo,w and $P_{\text {oes }}, \mathrm{W}$ was found in healthy subjects over a wide range of pressures obtained during whistles of different intensity. This predicts that the $P$ mo, W test will remain valid in patients with expiratory muscle weakness, a prediction supported by the data from ALS patients shown in figure 3. Most importantly, it was found that, in patients with ALS of varying severity, $P$ mo, W values strongly correlated with $P$ ga, W.
Dynamic nature of the manoeuvre. Unlike the PE,max test, which is based on a static manoeuvre, the whistle test is based on a dynamic one. With dynamic tests, concern can arise because airflow can render the manoeuvre not truly isovolumic. For the sniff this tendency is minimized because the nose acts as a Starling resistor, so that nasal flow is reduced, largely independent of driving pressure [21]. For the whistle, our in vitro assessment showed that flow increased with driving pressure and this might have resulted in $P$ mo,W being lower than $P$ E,max; this was not so, indicating that the volume expired before peak pressure is not sufficient to importantly detract from the value of the test. This is because the whistle orifice acts as a resistor, substantially reducing expiratory flow. In this regard, the mean value we measured in healthy subjects for peak flow through the device, was $92 \mathrm{~L} \cdot \mathrm{min}^{-1}$, approximately 6-8 times lower than their peak expiratory flow rate.

Recoil pressures. PE,max is normally measured at TLC because subjects find it easier to maximize expiratory efforts at high volumes. In this study the whistle test manoeuvre was also performed at TLC and, at this lung volume, the pressure measured reflected both the pressure developed by the expiratory muscles and the passive elastic recoil pressure of the respiratory system. Specifically, at TLC the passive elastic recoil pressure can add up to $40 \mathrm{cmH}_{2} \mathrm{O}$, equal to the pressure generated by the expiratory muscles [22]. However the whistle is a dynamic manoeuvre and recent data obtained using the peak expiratory flow [23] suggest the possibility that the recoil force generated by the chest wall might be greater in this situation than after the static manoeuvre. Whilst this might contribute to $P$ mo, W being higher than $P$ E,max, it does not explain the wide limits of agreement and therefore does not alter our conclusion that $P$ mo,W could be of value as a complementary test of expiratory muscle strength.

Facial muscles. Conceptually, the facial muscles might contribute to $P$ mo, W, although the orifice of the whistle should serve the same function as the mouth leak proposed by RINQvisT [13]. Consistent with this, the present study found no significant differences between $P$ mo, w measurements taken with or without cheek support and it is therefore concluded that this is not a matter of practical clinical importance.

Table 1. - Values of mouth whistle pressure $\left(P_{\mathrm{mo}}, \mathrm{W}\right)$, oesophagus whistle pressure $\left(P_{\mathrm{oes}}, \mathrm{W}\right)$, and gastric whistle pressure $(P$ ga, W $)$ during whistles ranging from minimal to maximal intensity performed by eight healthy subjects

\begin{tabular}{|c|c|c|c|c|c|c|c|c|}
\hline Subject & Whistles & $\begin{array}{c}P \mathrm{mo}, \mathrm{W} \\
\left(\mathrm{cmH}_{2} \mathrm{O}\right)\end{array}$ & $\begin{array}{c}P \text { oes, }, \mathrm{W} \\
\left(\mathrm{cmH}_{2} \mathrm{O}\right)\end{array}$ & $\begin{array}{c}P \mathrm{ga}, \mathrm{W} \\
\left(\mathrm{cmH}_{2} \mathrm{O}\right)\end{array}$ & $P_{\mathrm{mo}, \mathrm{W} / P_{\text {oes }}, \mathrm{W}}$ & $P_{\mathrm{mo}, \mathrm{W} / P_{\mathrm{ga}, \mathrm{W}}}$ & $\begin{array}{c}\mathrm{r} \\
P_{\mathrm{mo}, \mathrm{W}} \text { versus } P_{\mathrm{oes}, \mathrm{W}}\end{array}$ & $\begin{array}{c}\mathrm{r} \\
P \mathrm{mo}, \mathrm{W} \text { versus } P_{\mathrm{ga}, \mathrm{W}}\end{array}$ \\
\hline 1 & 42 & $13-151$ & $11-145$ & $15-177$ & $1.01(0.08)$ & $0.92(0.08)$ & 0.997 & 0.993 \\
\hline 2 & 52 & $11-153$ & $12-138$ & $13-147$ & $1.07(0.07)$ & $1.03(0.06)$ & 0.998 & 0.997 \\
\hline 3 & 44 & $18-177$ & $18-115$ & 22-196 & $1.15(0.20)$ & $0.83(0.07)$ & 0.984 & 0.998 \\
\hline 4 & 41 & $20-159$ & $20-161$ & $19-178$ & $0.96(0.05)$ & $0.76(0.12)$ & 0.997 & 0.971 \\
\hline 5 & 35 & $7-117$ & $4-119$ & $6-134$ & $1.09(0.19)$ & $0.87(0.10)$ & 0.999 & 0.998 \\
\hline 6 & 22 & $23-96$ & $20-99$ & $50-179$ & $1.09(0.08)$ & $0.51(0.06)$ & 0.989 & 0.964 \\
\hline 7 & 20 & $34-152$ & $20-87$ & $40-182$ & $1.82(0.39)$ & $0.90(0.12)$ & 0.864 & 0.986 \\
\hline 8 & 23 & $31-114$ & 26-104 & $32-117$ & $1.09(0.07)$ & $0.98(0.07)$ & 0.983 & 0.986 \\
\hline All & 278 & $7-222$ & $4-161$ & $9-235$ & $1.12(0.25)$ & $0.87(0.16)$ & 0.929 & 0.936 \\
\hline
\end{tabular}

Pressure data are given as ranges and ratios as mean \pm SD. $r$ : correlation coefficient. 


\section{Significance of the findings}

In healthy subjects, it was found that $P$ mo,W and $P$ E,max values correlated with wide limits of agreement, although $P$ mo, W values were significantly higher than $P$ E,max and in all but three subjects the $P$ mo,W/PE,max ratio was $>1$. In ALS patients, it was also found that $P$ mo, W and $P$ E,max values were closely related. $P$ mo, W mean values were numerically, but not statistically significantly, higher than those of $P \mathrm{E}$,max, and the $P$ mo, W/PE, max ratio was $>1$ in seven of the 10 patients.

Although the $P$ E,max manoeuvre is not complicated, it is not one with which many subjects will be familiar on a daily basis and requires full cooperation from subjects. In contrast, the whistle manoeuvre may be more natural and has the advantage of audible feedback. Low $P$ E, max values can occur even in healthy subjects, perhaps due to a lack of motivation or poor technique and thus may not indicate reduced expiratory muscle strength. Predicted $P$ E,max values are readily available for adults, the elderly, and children $[2,24]$ but the normal ranges are wide, making it difficult to accurately identify weakness. In the present study, the whistle manoeuvre was easily performed, with minimal instruction, and was well accepted both by healthy subjects and ALS patients. The high mouth pressures achieved and the relatively high lower limits suggest that the $P$ mo,W could be a clinically useful, additional method for assessing expiratory muscle strength. The day to day reproducibility of $P$ mo,W was good, suggesting the test could also be useful for serial measurements.

The ALS patients had variable severity of disease; some had severe respiratory muscle weakness whereas others had normal strength. In the patients, as in healthy subjects, the whistle manoeuvre was found to generate gastric, oesophageal and mouth pressures that were higher than those generated at $P$ E,max. In particular, $P$ ga values during whistle were significantly higher than those during $P \mathrm{E}, \max$, indicating that the whistle manoeuvre could better recruit abdominal muscle contraction than PE,max. Because of the small sample size, bulbar and nonbulbar patients were not specifically compared; clearly a theoretical concern could be that bulbar patients do not achieve satisfactory transmission of pleural pressure to the mouth during a whistle.

Interestingly, in ALS patients, Poes values were less than $P$ ga values during whistle, but were higher than $P$ ga values during $P$ E,max. This might suggest that the rib cage expiratory muscles play a different role during the two manoeuvres with a greater involvement during the $P$ E,max. Alternatively, one could hypothesize that the process of ALS leads to compensatory hypertrophy or recruitment of muscles not yet affected by the disease as suggested by ATTALI et al. [25].

$P$ mo,W and $P$ E,max values were significantly lower than corresponding cough $P$ ga values, both in healthy subjects and in ALS patients. Additionally, gastric pressure during whistle and $P$ E, max manoeuvres was numerically lower than cough $P$ ga. The present data confirm the results of a previous paper [1] that showed that cough is the most physiological expiratory manoeuvre and that cough $P$ ga is the gold standard for measuring pressure caused by abdominal muscle contraction. However, it was also observed that the bias and the limits of agreement between $P$ mo, W and cough $P$ ga were respectively smaller and narrower than those between $P$ E,max and cough $P$ ga, both in patients and healthy subjects. Additionally, in ALS patients, $P$ mo,W values did not significantly differ and were strictly related to cough Pga. Lastly, the shape of the pressure tracings recorded during the whistle manoeuvre were very similar to those during cough (fig. 5). Considered together, these findings suggest that whistle is a manoeuvre physiologically closer to cough than $P$ E,max.

In conclusion, this study indicated that, in both healthy subjects and in amyotrophic lateral sclerosis patients, mouth whistle pressure is an accurate reflection of expiratory muscle strength. The limits of agreement between mouth whistle pressure and maximum expiratory pressure were wide, suggesting a role for mouth whistle pressure as an additional method for the evaluation of expiratory muscle strength, for use in both in the physiology laboratory and in clinical settings.

\section{References}

1. Polkey MI, Lyall RA, Green M, Leigh PN, Moxham J. Expiratory muscle function in amyotrophic lateral sclerosis. Am J Respir Crit Care Med 1998; 158: 734 741.

2. Wilson SH, Cooke NT, Edwards RHT, Spiro SG. Predicted normal values for maximal respiratory pressures in caucasian adults and children. Thorax 1984; 39: 535-538.

3. Polkey MI, Green M, Moxham J. Measurement of respiratory muscle strength. Thorax 1995; 50: 1131-1135.

4. Black LF, Hyatt RE. Maximal respiratory pressures: Normal values and relationships to age and sex. $\mathrm{Am}$ Rev Respir Dis 1969; 99: 696-702.

5. Miller JM, Moxham J, Green M. The maximal sniff in the assessment of diaphragm function in man. Clin $\mathrm{Sci}$ 1985; 69: 91-96.

6. Laroche CM, Mier AK, Moxham J, Green M. The value of sniff esophageal pressures in the assessment of global inspiratory muscle strength. Am Rev Respir Dis 1988; 138: 598-603.

7. Heritier F, Rahm F, Pasche P, Fitting J-W. Sniff nasal pressure. A noninvasive assessment of inspiratory muscle strength. Am J Respir Crit Care Med 1994; 150: 1678-1683.

8. Fitting J-W, Paillex R, Hirt L, Aebischer P, Schluep M. Sniff nasal pressure: A sensitive respiratory test to assess progression of amyotrophic lateral sclerosis. Ann Neurol 1999; 46: 887-893.

9. Kyroussis D, Mills GH, Polkey MI, et al. Abdominal muscle fatigue after maximal ventilation in humans. $J$ Appl Physiol 1996; 81: 1477-1483.

10. Norris FH, Calanchini PR, Fallat RJ, Panchari S, Jewett B. The administration of guanidine in amyotrophic lateral sclerosis. Neurology 1974; 24: 721-728.

11. The ALS CNTF treatment study (ACTS) phase I-II study group. The amyotrophic lateral sclerosis functional rating scale. Assessment of activities of daily living in patients with amyotrophic lateral sclerosis. Arch Neurol 1996; 53: 141-147.

12. Quanjer $\mathrm{PhH}$, Tammeling GJ, Cotes JE, et al. Lung 
volumes and forced ventilatory flows. Eur Respir $J$ 1993; 6: Suppl. 16, 5-40.

13. Ringqvist T. The ventilatory capacity in healthy subjects: an analysis of causal factors with special reference to the respiratory forces. Scand J Clin Invest 1966; 18: (Suppl. 88), 8-170.

14. Milic-Emili J, Mead J, Turner JM, Glauser EM. Improved technique for estimating pleural pressure from esophageal balloms. J Appl Physiol 1964; 19: 207-211.

15. Laporta D, Grassino A. Assessment of transdiaphragmatic pressure in humans. J Appl Physiol 1985; 58: 1469-1176.

16. Bland JM, Altman DG. Statistical methods for assessing agreement between two methods of clinical measurements. Lancet 1986; i: 307-310.

17. Armitage P, Berry G. Statistical methods in medical research. 3rd ed. Blackwell, Oxford, 1994; pp. 273276.

18. De Troyer A, Estenne M, Ninane V, Van Gansbeke D, Gorini M. Transversus abdominis muscle function in humans. J Appl Physiol 1990; 68: 1010-1016.
19. De Troyer A, Sampson M, Sigrist S, Kelly S. How the abdominal muscles act on the rib cage. J Appl Physiol 1983; 54: 465-469.

20. Mier A, Brophy C, Estenne M, et al. Action of abdominal muscles on rib cage in humans. $J$ Appl Physiol 1985; 58: 1438-1443.

21. Pertuze J, Watson A, Pride NB. Limitation of maximal inspiratory flow through the mouth. Clin Sci 1987; 23: $34 \mathrm{~s}$.

22. Rochester DF. Tests of respiratory muscle function. Clin Chest Med 1988; 9: 249-261.

23. D'Angelo E, Prandi E, Milic-Emili J. Dependence of maximal flow-volume curves on time course of preceding inspiration. J Appl Physiol 1993; 75: 11551159.

24. McElvaney G, Blackie S, Morrison NJ, et al. Maximal static respiratory pressures in the normal elderly. Am Rev Respir Dis 1989; 139: 277-281.

25. Attali V, Mehiri S, Straus C, et al. Influence of neck muscles on mouth pressure response to cervical magnetic stimulation. Am J Respir Crit Care Med 1997; 156: 509-514. 